\title{
Editorial: Effects of surface heterogeneity in adsorption and catalysis on solids
}

\author{
ISSHAC-8: Eight International Symposium, Poland, Kraków, 27-31 August, 2012
}

\author{
Wladek Rudziński
}

Received: 22 February 2013/ Accepted: 25 February 2013/Published online: 14 March 2013

(C) The Author(s) 2013. This article is published with open access at Springerlink.com

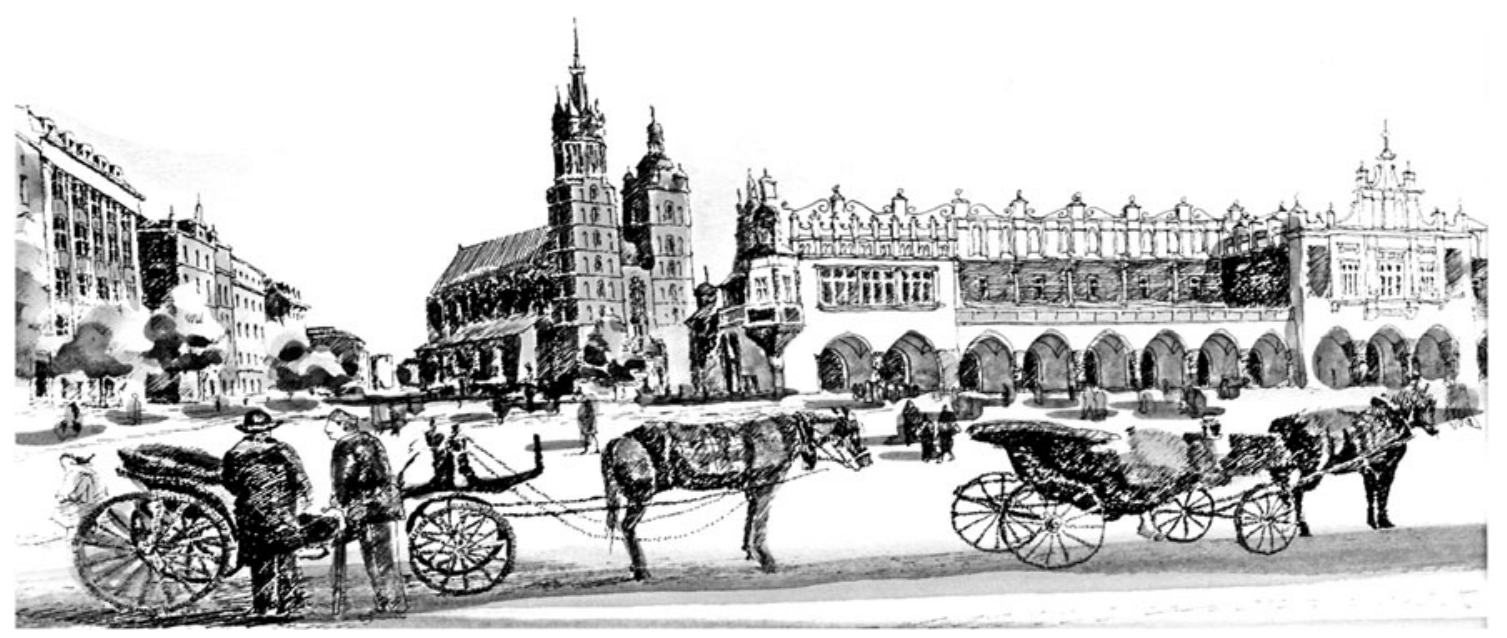

Geometric and energetic heterogeneities constitute a fundamental feature of solid surfaces and are of great interest in the study of adsorption. There is also the evidence that these effects play an important role in catalysis, but their importance in catalysis is not well understood.

To share and broaden our understanding of the phenomena involved we have organized a series of symposia devoted specially to the influence of surface heterogeneity on adsorption and catalysis. Over the years these have served as a forum for an intensive exchange of ideas, opinions, and theoretical approaches defining the state of the art and fostering progress in this field.

The ISSHAC symposium has been known for its unique symposium style. The symposium program is ample and there is little time for formal discussions. Instead, the

W. Rudziński ( $\square)$

UMCS, Lublin, Poland

e-mail: Wladyslaw.Rudzinski@umcs.lublin.pl program places emphasis on the creation of a maximum number of opportunities for informal discussion and facilitation of direct person-to-person exchanges of ideas. The extended social program provides numerous opportunities for such informal discussion. Interaction-encouraging social programs are offered every day in the late afternoon and evening.

In organizing the first event and subsequent ISSHAC symposia we have followed the principle that each symposium should be located in a different but attractive place, to offer an opportunity for participants to enjoy the science, the collegiality, and the cultural ambience at each meeting. In doing this, we have followed the timeless Roman dictum that the "spirit of place", the ambiance, is crucial to the success of an enterprise.

The present ISSHAC-8 symposium was held in Krakowthe historical capital of Poland.

Krakow was a place where, through many ages and twists of fate, various cultures met, creating a unique local 
On the left Prof. Wladek

Rudziński, The Chair of

Scientific Committee. On the

right Dr. Jolanta Michalek, The

Chair of Organizing Committee

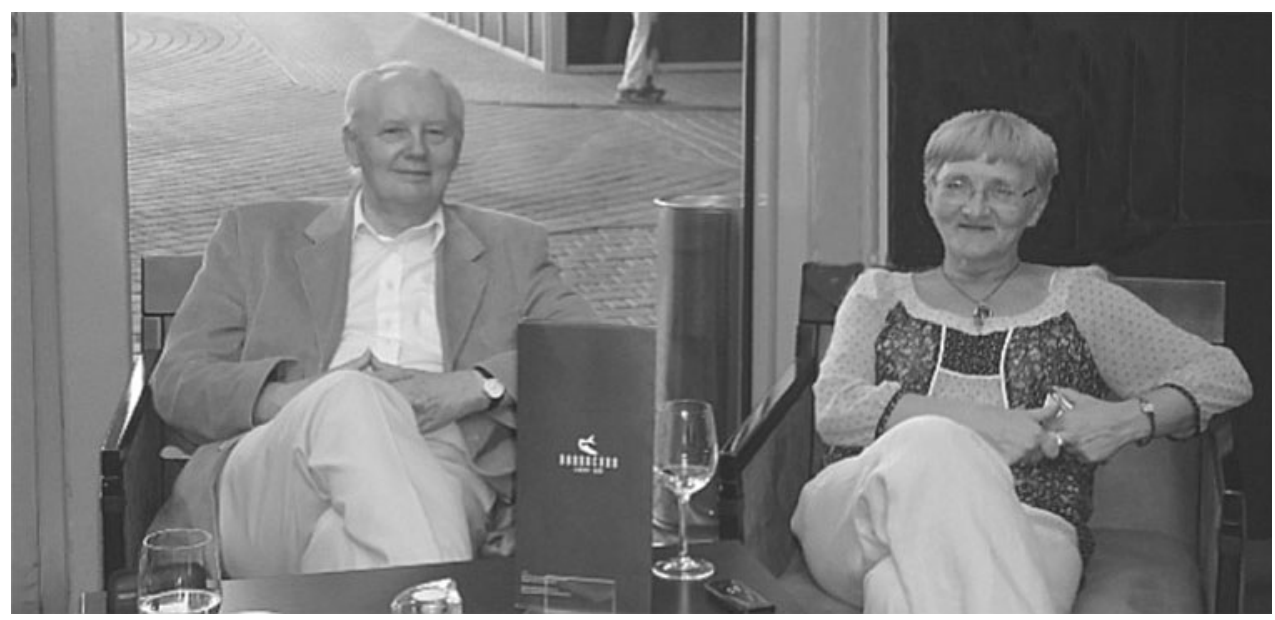

colour and a very special atmosphere, both well preserved by many traditions and local customs. Those who have visited Krakow find it a magical city. Its charm and antiquity combined with a sophisticated urban modernity make the attractions of the old town readily available without making them outdated or alien or too "museal".

168 active participants and 30 accompanying persons attended the ISSHAC- 8 Symposium. There were 78 oral and 114 poster presentations.
Special thanks are forwarded to those of the active participants who have contributed their papers to this special issue of ADSORPTION devoted to the present ISSHAC-8 Symposium.

Open Access This article is distributed under the terms of the Creative Commons Attribution License which permits any use, distribution, and reproduction in any medium, provided the original author(s) and the source are credited. 